\title{
Rare Adult Masseteric Rhabdomyosarcoma and a Review of the Literature
}

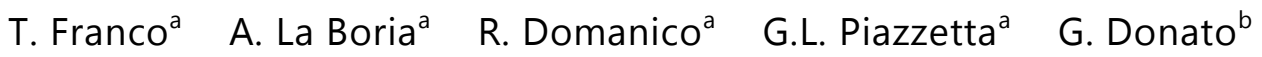 \\ E. Allegra ${ }^{a}$ \\ Departments of a Otolaryngology - Head and Neck Surgery, and ${ }^{\mathrm{b}}$ Pathology, University of \\ Catanzaro, Catanzaro, Italy
}

\section{Key Words}

Adult rhabdomyosarcoma $\cdot$ Alveolar rhabdomyosarcoma $\cdot$ Head and neck rhabdomyosarcoma $\cdot$ Masseter neoplasm

\begin{abstract}
Background: Rhabdomyosarcomas (RMSs) are a group of soft-tissue malignant tumors which derive from primitive skeletal muscle tissue that mainly affect children and adolescents. RMSs are very rare in adults, where they are usually located in the extremities. Case Presentation: A previously healthy 32-year-old male presented at our ENT (ear, nose and throat) outpatient clinic after experiencing a parotid region swelling for 2 months. The patient was treated surgically by excising the mass and by modified radical ipsilateral neck dissection. Histological and immunohistochemical examination indicated masseteric alveolar RMS with lymphatic metastasis. The patient received radiochemotherapy, and he is still alive with no evidence of disease spread 1 year after diagnosis. Conclusion: This is the first case of a masseter alveolar RMS to be reported in the literature in a patient older than 25 years; it highlights the broad spectrum of neoplasms that cause parotid region swellings and the importance of considering rare tumors during differential diagnosis.
\end{abstract}

\section{Introduction}

Rhabdomyosarcomas (RMSs) are a group of soft-tissue malignant tumors which derive from primitive skeletal muscle tissue and affect children and adolescents. RMSs account for approximately $60 \%$ of sarcomas in children under 15 years of age [1]. 
Franco et al.: Rare Adult Masseteric Rhabdomyosarcoma and a Review of the Literature

RMSs are classified according to their location in the extremities versus axial lesions; the latter subgroup arises from the head and neck, the paraspinal region, and the genitourinary tract [2].

The head and neck region is the most common axial site in children, and these RMSs are divided into three subgroups: orbital, parameningeal, and nonorbital nonparameningeal [3].

The International Classification divides RMSs into three histological subgroups with different prognoses: the embryonal subtype with two variants, i.e. spindle cell and botryoid, with a better prognosis; the alveolar subtype; and unspecified RMS with a poor prognosis [4].

Most RMSs are sporadic, and there is no evidence of risk factors, although a small subgroup is linked with familiar syndromes such as neurofibromatosis and Li-Fraumeni syndrome [5]. Chemello et al. [6] also reported a case of embryonal RMS of the masseter muscle in a 12-year-old girl, who had previously been irradiated for a bilateral retinoblastoma.

\section{Case Presentation}

A previously healthy 32-year-old male nonsmoker presented at our ENT (ear, nose and throat) outpatient clinic complaining of a painless swelling in the right parotid region, which had been increasing for 2 months. The macroscopic examination reported a firm mass measuring about $3.5 \times 1.5 \mathrm{~cm}$ with shaded limits, while ipsilateral lymphadenopathy was also present. No other ENT diseases were identified during the physical examination. The preoperative baseline parameters and chest X-ray were normal. Hematological and infectious diseases were evaluated, but both pathologies were negative based on hematological and microbiological examinations.

The patient was submitted to neck ultrasound, which identified a hyperechogenic nodular mass measuring about $2.5 \times 1.3 \mathrm{~cm}$ in the right parotid region, with concomitant ipsilateral enlarged cervical nodes.

Multislice computed tomography (CT) detected a mass in the right masseter with a maximum diameter of approximately $2.2 \mathrm{~cm}$ with central necrosis and perifocal inflammatory reaction, which was associated with thickening of the masseter muscle. At the lower parotid pole, there was a coexisting area of high enhancement, while multiple enlarged cervical nodes were found in the level III and IV cervical nodes, with a diameter of $1-1.8 \mathrm{~cm}$ (fig. 1, fig. 2).

Magnetic resonance imaging (MRI) with paramagnetic contrast identified an oval mass in the right masseter muscle, which was mildly hyperintense in T1-weighted images and hyperintense in long repetition time (TR), with regular margins and high contrast intake. The concomitant low pole mass had a cystic appearance with regular margins and low intensity in T1-weighted images and a higher intensity in short tau inversion recovery (STIR). Right lymphadenopathy was confirmed (fig. 3).

The patient was also submitted to ${ }^{18} \mathrm{~F}-\mathrm{FDG}$ positron emission tomoscintigraphy (PET), which indicated a high pathological increase in the glucose metabolism in the intramasseteric right region [maximum standardized uptake value (SUV max) 10.5], right jugular nodes, right submandibular nodes (SUV max 6.6), and right cervical nodes (SUV max 6.7). These were all suspected neoplastic locations (fig. 4).

Surgical treatment was proposed to the patient, and he gave written informed consent for treatment and case report publication. Ethical approval was received by the Institutional Review Board of 'Magna Graecia' University of Catanzaro, Italy. Thus, the patient was treated 
Franco et al.: Rare Adult Masseteric Rhabdomyosarcoma and a Review of the Literature

surgically by removal of the masseteric mass and by modified radical ipsilateral neck dissection. During surgery, the tumor appeared irregularly limited and it was strongly adherent to the mandibular bone surface and the masseter, with a colliquative lower pole. Postoperative tests were regular and the patient was discharged on the 5th postoperative day.

Histological examination identified alveolar RMS in the right masseter mass and 44 cervical nodes (superficial periparotid node, intraparotid node, and levels IIA-IIB-III-IV-V right cervical nodes), with small and intermediate-sized round tumor cells according to hematoxylin and eosin stain (fig. 5) and widespread nuclear immunoreactivity to myogenin (fig. 6).

The tumor was classified according to the Intergroup Rhabdomyosarcoma Study (IRS) postsurgical pathological system as Group IIa (table 1).

The patient received radiochemotherapy with radiation at $45 \mathrm{~Gy}$, while chemotherapy consisted of 14 cycles of vincristine, dactinomycin, and cyclophosphamide (VAC).

The patient received a strict follow-up protocol with 3-monthly checks. He was free of locoregional disease with no evidence of distant metastasis 1 year after diagnosis.

\section{Discussion}

Differential diagnosis of masseter muscle enlargement involves several diseases. The most frequent cause is benign masseteric hypertrophy, followed by hemangioma.

A masseter mass associated with an ipsilateral lymphadenopathy may be diagnosed as an infectious disease (e.g. epidemic parotitis or cat scratch disease) or a malignant neoplasm, such as non-Hodgkin's lymphoma or sarcoma. Metastatic lesions in the masseter have been reported in the literature [7].

RMSs are malignant tumors with a mesenchymal origin, which arise from cells committed to a skeletal muscle lineage that initiate myogenic differentiation but fail to disconnect from their proliferative cycle [2]. They are related to somatic development alterations, which might explain the high likelihood of these tumors in children [8].

A recent data collection by the Surveillance Epidemiology and End Result (SEER) registry [3] found that one third of head and neck RMSs affected adults (20-55 years, 23.1\%; >55 years, $8.1 \%$ ) with no gender bias, where the main localization was a parameningeal site with the embryonal histological subtype.

La Quaglia et al. [9] reported data from a combined pediatric and adult RMS database, where they found that $14.6 \%$ of RMSs affected patients older than 30 years of age and were typically localized in the extremities, while the head and neck region accounted for only $18 \%$ of all adult RMSs. Adult RMSs mainly belonged to the embryonal and pleomorphic subtypes.

Hawkins et al. [10] evaluated data from 84 adult RMSs and identified the head and neck region and extremities as the most frequent sites, accounting for 24 and $22 \%$ of tumors, respectively. Embryonal was the most common histological subtype (53\%), followed by alveolar (30\%).

Little et al. [11] reported data on 82 adult RMSs and identified the head and neck region as the most common site (52\%), while most RMSs belonged to the pleomorphic and embryonal histological subtypes.

Literature case series are heterogeneous, with few studies distinguishing adult data from child data, and they do not divide head and neck case series according to the site.

The alveolar subtype has the worst prognosis because of its great propensity for lymph node metastasis. 
Turner and Richmon [3] reported 24\% alveolar subtype RMSs in the head and neck region, and there was a significant survival difference between the alveolar and embryonal subtypes (44.1 and $72.2 \%$ at 5 years, respectively). Hawkins et al. [10] reported that $32 \%$ belonged to the alveolar subtype in an adult RMS series, and 32\% affected the head and neck region. Little et al. [11] reported that $23 \%$ belonged to the alveolar subtype of tumors in an adult RMS series, while $63 \%$ were locally extended at diagnosis.

An adult RMS treatment protocol has not yet been established. Little et al. [11] confirmed that the therapeutic goal is typically complete surgical excision followed by chemoradiotherapy. In their series, $45 \%$ of RMSs, half of which were located in the head and neck region, were not surgically removable. Management of regional lymph nodes was based on neck dissection followed by radiotherapy. They confirmed that regional treatment should be included in the overall treatment strategy for the alveolar RMS subtype because of its higher incidence of lymphatic metastasis. Systemic chemotherapy, based on dactinomycin or doxorubicin combined with vincristine and cyclophosphamide, was provided to $71 \%$ of patients. There was a median survival time of 38 months for all adult patients, with a 10year actuarial disease and overall survival rate of 41 and $40 \%$, respectively. Moreover, patients that responded to chemotherapy had a longer metastasis-free period $(72 \%$ at 10 years) than nonresponders (19\% at 10 years).

Pterygo-masseteric complex RMS is very rare in adults. Raney et al. [12] reported data from the IRS Group III and IV protocols in patients younger than 21 years and identified 5 masseter RMSs (10.6\%), of which only 1 was an alveolar RMS. Chemello et al. [6] reported a case of embryonal RMS in a 12-year-old girl affected by bilateral retinoblastoma. ToranzoFernandez et al. [13] reported a case of alveolar masseter RMS in a child, while Reynard and Brinkley [14] reported an alveolar masseter RMS in a 16-year-old boy. Yamada et al. [15] described a masseter alveolar RMS in a 22-year-old man. All reported masseter RMSs were treated by surgical removal followed by chemoradiotherapy with a poor prognosis, and most patients died after locoregional recurrence.

\section{Conclusion}

This is the first case of a masseter alveolar RMS reported in literature in an Italian patient older than 25 years. This case highlights the broad spectrum of neoplasms causing parotid region swellings and the importance of considering rare tumors during differential diagnosis.

\section{Disclosure Statement}

The authors have no conflicts of interest.

\section{References}

1 Dagher R, Helman L: Rhabdomyosarcoma: an overview. Oncologist 1999;4:34-44.

-2 Parham DM, Ellison DA: Rhabdomyosarcomas in adults and children, an update. Arch Pathol Lab Med 2006;130:1454-1465.

-3 Turner JH, Richmon JD: Head and neck rhabdomyosarcoma: a critical analysis of population-based incidence and survival data. Otolaryngol Head Neck Surg 2011;145:967-973.

-4 Newton WA Jr, Gehan EA, Webber BL, Marsden HB, van Unik AJ, Hamoudi AB, Tosokos MG, Shimada H, Harms D, Schmidt D, et al: Classification of rhabdomyosarcoma and related sarcomas. Pathologic aspects 
Franco et al.: Rare Adult Masseteric Rhabdomyosarcoma and a Review of the Literature

and proposal for a new classification - an Intergroup Rhabdomyosarcoma Study. Cancer 1995;76:10731085.

5 Dantonello TM, Int-Veen C, Winkler P, Leuschner I, Schuck A, Schmidt BF, Lochbuehler H, Kirsch S, Hallmen E, Veit-Friedrich I, Bielack SS, Niggli F, Kazanowska B, Ladenstein R, Wiebe T, Kingebiel T, Treuner J, Koscielniak E: Initial patient characteristics can predict pattern and risk of relapse in localized rhabdomyosarcoma. J Clin Oncol 2008;26:406-413.

6 Chemello PD, Nelson CL, Tomich CE, Sadove AM: Embryonal rhabdomyosarcoma arising in the masseter muscle as a second malignant neoplasm. J Oral Maxillofac Surg 1988;46:899-905.

7 Ahuja AT, King AD, Bradley MJ, Yeo WW, Mok TS, Metreweli C: Sonographic findings in masseter muscle metastases. J Clin Ultrasound 2000;28:299-302.

-8 Joshi D, Anderson JR, Paidas C, Breneman J, Parham DM, Crist W, Soft Tissue Sarcoma Committee of the Children's Oncology Group: Age is an independent prognostic factor in rhabdomyosarcoma: a report from the Soft Tissue Sarcoma Committee of the Children's Oncology Group. Pediatr Blood Cancer 2004;42:64-73.

-9 La Quaglia MP, Heller G, Ghavimi F, Casper ES, Vlamis V, Hajdu S, Brennan MF: The effect of age at diagnosis on outcome in rhabdomyosarcoma. Cancer 1994;73:109-117.

10 Hawkins WG, Hoos A, Antonescu CR, Urist MJ, Leung DH, Gold JS, Woodruff JM, Lewis JJ, Brennan MF: Clinicopathologic analysis of patients with adult rhabdomyosarcoma. Cancer 2001;91:794-803.

-11 Little DJ, Ballo MT, Zagars GK, Pisters PW, Patel SR, El-Naggar AK, Garden AS, Benjamin RS: Adult rhabdomyosarcoma: outcome following multimodality treatment. Cancer 2002;95:377-388.

12 Raney RB, Chintagumpala M, Anderson J, Pappo A, Qualman S, Wharam M, Wiener E, Meyer W, Soft-Tissue Sarcoma Committee of the Children's Oncology Group, Arcadia, California: Results of treatment of patients with superficial facial rhabdomyosarcomas on protocols of the Intergroup Rhabdomyosarcoma Study Group (IRSG), 1984-1997. Pediatr Blood Cancer 2008;50:958-964.

13 Toranzo-Fernandez JM, Noyola-Frias MA, Sanchez-Hermosillo E, Gonzalez-Mendoza E: Rhabdomyosarcoma in children: a report of two cases. J Clin Pediatr Dent 2000;25:87-90.

14 Reynard M, Brinkley JR Jr: Cavernous syndrome caused by rhabdomyosarcoma. Ann Ophthalmol 1983;15:94-97.

15 Yamada H, Mishima K, Kawaguchi K, Horiuchi T, Nakaoka K, Iino M, Saito I, Hamada Y: A nodular buccal mass. Oral Surg Oral Med Oral Pathol Oral Radiol Endod 2010;110:140-144.

Table 1. IRS Group postsurgical pathologic group

\begin{tabular}{ll}
\hline Group & Definition \\
\hline Group I & $\begin{array}{l}\text { Localized tumor, completely removed with pathologically clear margins and no regional } \\
\text { lymph node involvement }\end{array}$ \\
Group II & $\begin{array}{l}\text { Localized tumor, grossly removed with: } \\
\text { (a) microscopically involved margins; }\end{array}$ \\
Group III & $\begin{array}{l}\text { Localized tumor, with gross residual disease after grossly incomplete removal, or biopsy } \\
\text { only } \\
\text { Distant metastases present at diagnosis }\end{array}$ \\
Group IV &
\end{tabular}




\section{Case Reports in Oncology}

\begin{tabular}{l|l}
\hline Case Rep Oncol 2013;6:472-479 \\
\hline DOI: $10.1159 / 000355250$ & $\begin{array}{l}\text { @ 2013 S. Karger AG, Basel } \\
\text { www.karger.com/cro }\end{array}$ \\
\hline
\end{tabular}

Franco et al.: Rare Adult Masseteric Rhabdomyosarcoma and a Review of the Literature

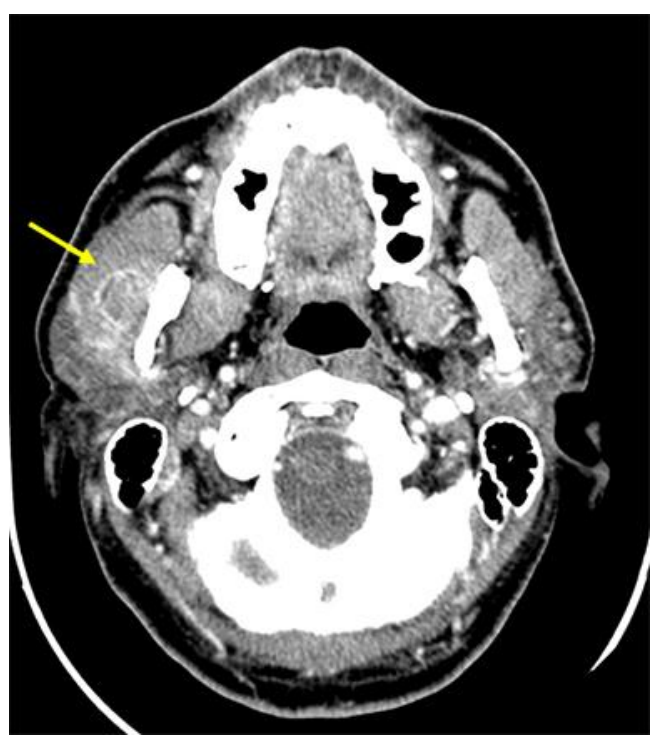

Fig. 1. Multislice CT showing the mass in the right masseter with central necrosis and perifocal inflammatory reaction, associated with thickening of the masseter muscle.

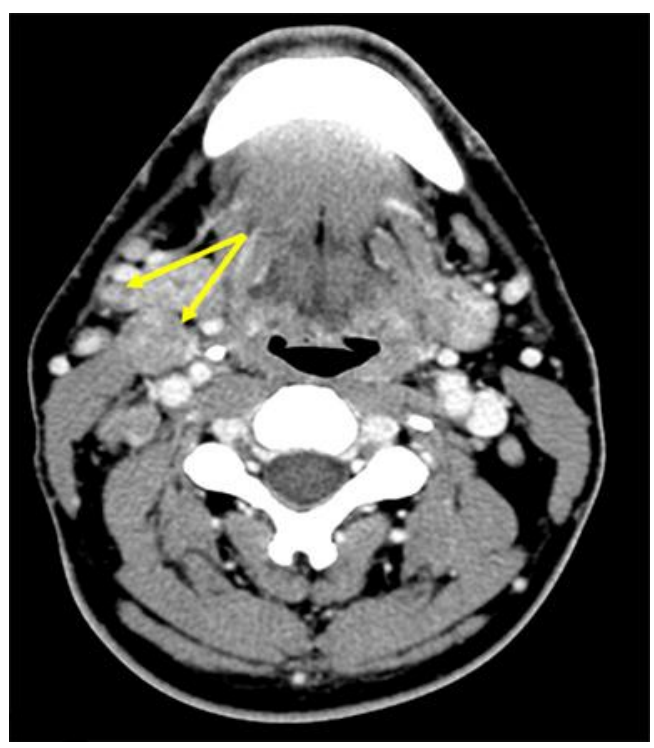

Fig. 2. Multislice CT. Coexisting areas of high enhancement are visible at the lower parotid pole with multiple cervical lymphadenopathies at the level III and IV cervical nodes. 


\section{Case Reports in Oncology}

\begin{tabular}{l|l}
\hline Case Rep Oncol 2013;6:472-479 \\
\hline DOI: 10.1159/000355250 & $\begin{array}{l}\text { ○ 2013 S. Karger AG, Basel } \\
\text { www.karger.com/cro }\end{array}$ \\
\hline
\end{tabular}

Franco et al.: Rare Adult Masseteric Rhabdomyosarcoma and a Review of the Literature

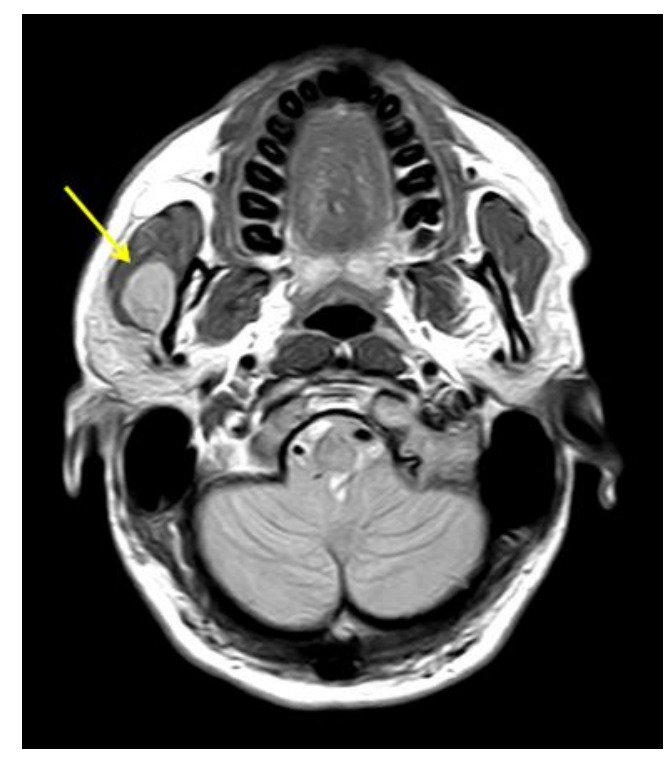

Fig. 3. MRI showing an oval mass in the right masseter muscle, which was mildly hyperintense in T1weighted images and hyperintense in long TR, with regular margins and a high contrast intake.

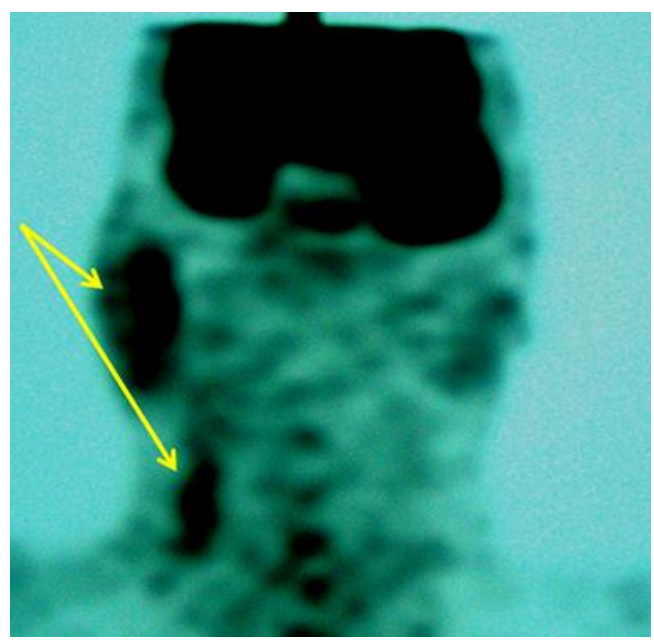

Fig. 4. PET. Pathological increase in glucose metabolism in the intramasseteric right region (SUV max 10.5), right jugular nodes, right submandibular nodes (SUV max 6.6), and right cervical nodes (SUV max $6.7)$. 


\section{Case Reports in Oncology}

\begin{tabular}{l|l}
\hline \multicolumn{2}{l}{ Case Rep Oncol 2013;6:472-479 } \\
\hline DOI: $10.1159 / 000355250$ & $\begin{array}{l}\text { C 2013 S. Karger AG, Basel } \\
\text { www.karger.com/cro }\end{array}$ \\
\hline
\end{tabular}

Franco et al.: Rare Adult Masseteric Rhabdomyosarcoma and a Review of the Literature

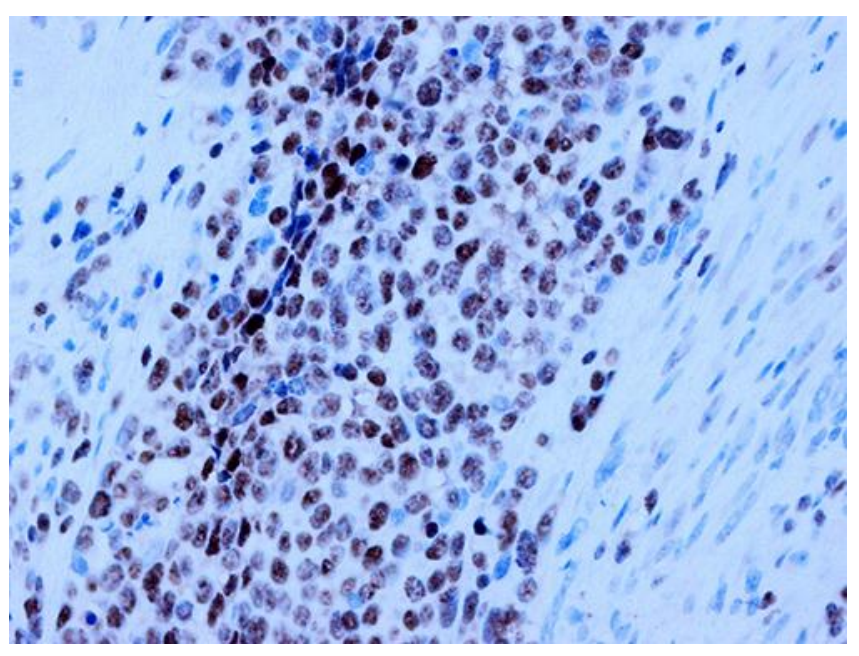

Fig. 5. Histopathological and immunohistochemical features of alveolar RMS. Hematoxylin and eosin stain (40x): small and intermediate-sized round tumor cells are visibly separated by connective tissue septa.

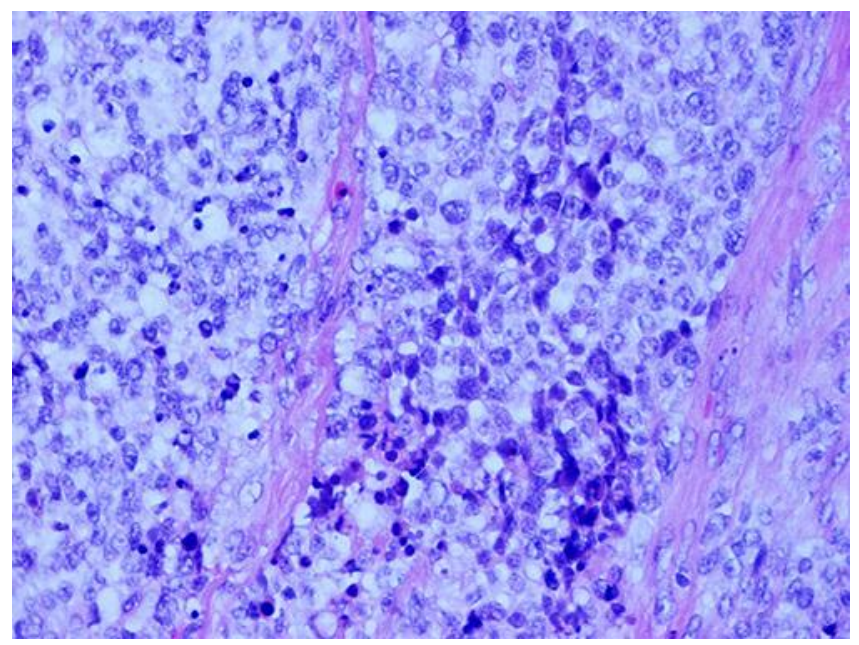

Fig. 6. Histopathological and immunohistochemical features of alveolar RMS. Widespread nuclear immunoreactivity against myogenin (40x). 